DOI 10.1590/1807-01912014202157

OPCampinasV20N2

\title{
Comportamento eleitoral e estratégia partidária nas eleições presidenciais no Brasil $(2002-2010)$
}

\begin{tabular}{c}
\hline \hline Fernando Guarnieri \\
Centro de Estudos da Metrópole \\
Universidade de São Paulo \\
\hline \hline
\end{tabular}

\begin{abstract}
Resumo: Neste artigo utilizo o Modelo Unificado do Voto de Adams, Merril e Grofman (2005) para compreender melhor o papel das estratégias partidárias e da identificação partidária na decisão do voto. Utilizo o algoritmo NOPP, derivado do trabalho de Adams et al, e os dados do ESEB para verificar as estratégias adotadas pelos candidatos nas três últimas eleições para presidente no Brasil. Enquanto este modelo proporcionou uma boa aproximação da posição dos candidatos do PSDB e de outros partidos que se posicionaram mais ao centro e à direita, ele não foi muito preciso no posicionamento dos candidatos do PT e de outros partidos que se posicionavam mais à esquerda. Isto indica que estes partidos se movem menos pela maximização de votos do que por outros fatores.
\end{abstract}

Palavras-chave: voto; eleições presidenciais; ESEB; modelos espaciais; estratégias partidárias

Abstract: In this article I use the Unified Model of Vote from Adams, Merrill and Grofman (2005) to better understand the role of party strategies and party identification in the voter decision. I use the NOPP algorithm, derived from the work of Adams et al, and data from the ESEB to check the strategies adopted by the candidates in the last three presidential elections in Brazil. While this model provided a good approximation of the position of the PSDB candidates and other parties that were positioned more to the center and right it was not very precise in positioning the PT candidates and other parties that are positioned more to the left. This indicates that these parties move less by maximizing votes than by other factors.

Keywords: voting; elections; ESEB; spatial models; party strategies 


\section{OPINIÃO PÚBLICA, Campinas, vol. 20, no 2, agosto, 2014, p. 157-177}

\section{Introdução ${ }^{1}$}

Até recentemente a literatura sobre competição eleitoral estava dividida entre uma perspectiva na qual os eleitores votariam em partidos que estivessem mais próximos à sua posição ideológica e outra perspectiva onde os eleitores escolheriam partidos com os quais teriam estabelecido uma ligação de natureza psicológica. Essas perspectivas são a base das teorias sociológica/econômica do voto e da teoria psicológica do voto.

Conforme a primeira perspectiva os partidos competiriam por votos posicionando-se o mais próximo possível da posição da maior parte dos eleitores. No caso de dois partidos competindo em uma eleição dominada por um tema (uma dimensão) esses partidos convergiriam para a posição do eleitor mediano. Portanto, esta perspectiva privilegia a estratégia partidária como fator explicativo do resultado eleitoral.

$\mathrm{Na}$ segunda perspectiva os eleitores votam nos partidos independentemente da estratégia destes. A escolha do eleitor se daria em função de atitudes frente à política formadas desde a sua infância no processo de socialização da criança. As atitudes se combinam em um sistema de crenças coerente. $O$ eleitor daria seu voto a partidos que compartilhassem desse sistema de crenças.

$\mathrm{Na}$ sua forma pura, estas duas teorias levariam ou à falta de competição ou à imprevisibilidade dos resultados. Na primeira perspectiva ou os partidos convergem para o centro ou então, quando entram mais partidos na disputa, o resultado se torna indeterminado. Na segunda perspectiva a configuração da competição seria estável e duradoura, variando apenas com as identidades políticas desenvolvidas e com o grau de engajamento. Quando as identidades são fracamente desenvolvidas o sistema se tornaria instável.

O problema com que se deparam pesquisadores que trabalham com ambas as perspectivas é que essas consequências não encontram suporte empírico. Quase inexistem situações em que os partidos/candidatos não difiram, mesmo que pouco, em suas propostas e em suas mensagens e os resultados eleitorais são, em boa parte, previsíveis embora dinâmicos.

Essa dificuldade fez com que vários autores propusessem adaptações desses modelos. Recentemente Adams, Merrill e Grofman (2005) propuseram uma teoria unificada da competição partidária segundo a qual fatores não-programáticos, como a identificação partidária, afetariam o posicionamento estratégico dos partidos. Conforme esses autores:

\footnotetext{
"To put it simply (in terms familiar to many political scientists), in this book we show how to reconcile the spatial-modeling traditions of the University of Rochester with the behaviorial traditions of the University of Michigan and Columbia" (AdAMS et al, 2005, p.2).
}

Essa teoria daria conta da divergência nas posições assumidas pelos partidos em diferentes contextos, como foi demonstrado pelos autores e por vários outros (JESSE, 2009; ADAMS, CLARK, EZROW \& Glasgow, 2006; Hellwig, 2008; Calvo e Hellwig, 2005).

\footnotetext{
${ }^{1} \mathrm{O}$ autor contou com o apoio da FAPESP por meio das bolsas n 2009/14768.2 e n 2013/04514-9.
} 
GUARNIERI, F. Comportamento eleitoral e estratégia partidária nas eleições...

Neste artigo utilizo o modelo de Adams et al (2005) para compreender melhor o papel das estratégias partidárias e da identificação partidária na decisão do voto. Deste modo pretendo contribuir para uma questão que tem pautado o debate sobre as eleições no período recente, utilizando o algoritmo sugerido por Adams et al e os dados do ESEB para verificar as estratégias adotadas pelos candidatos nas três últimas eleições para presidente no Brasil.

O artigo está organizado da seguinte maneira: na próxima seção faço uma breve revisão da literatura nacional sobre o impacto da identificação ideológica e partidária nas eleições presidenciais brasileiras. Na terceira seção descrevo o modelo Adams et al e o modo como irei utilizá-lo para recuperar a posição dos candidatos nas três últimas eleições para o governo federal. Na quarta seção utilizo os dados do ESEB para investigar os determinantes das estratégias destes candidatos. A quinta e última seção traz as considerações finais.

\section{Ideologia e identificação partidária nas eleições presidenciais brasileiras}

Como vota o eleitor brasileiro? Como o comportamento do eleitor afeta as estratégias partidárias? Essas são as duas questões centrais na pesquisa sobre competição eleitoral. Se conseguirmos identificar quais fatores determinam o voto do eleitor e como os partidos responderão estrategicamente a esses fatores conseguiremos prever, dentro de uma margem de erro, o resultado das eleições e o tipo de política que será adotada pelo vencedor.

As respostas dadas pela Ciência Política a essas questões são resumidas nos trabalhos de Figueiredo (1991) e Castro (1994). No Brasil os determinantes do comportamento eleitoral foram objeto de uma extensa bibliografia que floresce nos anos 1970 e 1980 (ver Lima Jr., 1999). Carreirão (2007b) traz uma revisão da literatura mais recente e dá destaque a dois fatores explicativos do voto derivados das duas abordagens examinadas acima: a identidade ideológica, derivada da teoria sociológica e da teoria econômica do voto, e o sentimento partidário, derivado da teoria psicológica do voto.

A identidade ideológica ${ }^{2}$ é introduzida na pesquisa brasileira sobre comportamento eleitoral por Singer (1999). Esse autor defende que a autolocalização dos eleitores em uma escala esquerda-direita seria um fator central na decisão do voto. Carreirão (2002) testa a tese de Singer confirmando o poder preditivo da identificação ideológica, mas relativizando seu impacto que variaria com a escolaridade do eleitor.

Holzhacker e Balbachevsky (2007), analisando as eleições presidenciais de 2002 e 2006 utilizando os dados do ESEB, agregam ao autoposicionamento ideológico a avaliação do governo e a simpatia do eleitor com Lula, candidato vitorioso naquelas eleições. A conclusão das autoras é que enquanto estas variáveis teriam sido todas importantes na decisão do voto em 2002, em 2006, a identificação ideológica não teria sido tão importante.

A mesma conclusão, de que a identificação ideológica teria baixo poder explicativo nas eleições de 2006, é apresentada por Carreirão (2007b). O autor testa a hipótese de que com a chegada do PT ao

\footnotetext{
2 Segundo Singer, "depois que a escola psicossociológica demonstrou, no final da década de 1950, que o público pensava de modo 'desestruturado', a ideologia, valorizada tanto pela corrente sociológica quanto pela econômica de explicação do voto, havia entrado em quarentena. Foi necessário reelaborar o uso do conceito de ideologia para fins de explicação do voto chegando ao de identificação ideológica... A identificação ideológica passa a ser vista como a adesão a uma posição no contínuo esquerda. direita ou liberal-conservador que, mesmo sendo difusa, isto é, cognitivamente desestruturada, sinaliza uma orientação política geral do eleitor" (SINGER, 1999, p.49).
} 


\section{OPINIÃO PÚBLICA, Campinas, vol. 20, no 2, agosto, 2014, p. 157-177}

poder e com as denúncias de corrupção que atingiram o governo o eleitor de Lula em 2006 decidiria menos com base em sua identificação ideológica e partidária do que em 2002. Embora Carreirão tenha confirmado que em 2006 a identificação ideológica esteve pouco associada com o voto ele constatou uma forte associação entre voto e "sentimento partidário"3.

Portanto, a identificação ideológica seria parte da resposta à questão de como o eleitor vota. Parece ter havido um declínio de sua importância com o tempo, mas o autoposicionamento no contínuo esquerda-direita ainda seria um importante preditor do voto. Para entender mais a fundo as motivações do eleitor precisamos olhar para a outra parte da resposta: para o sentimento partidário.

A influência da identificação partidária na explicação do voto no período recente foi examinada nos trabalhos Carreirão e Kinzo (2004) e Braga e Pimentel (2011). Esses trabalhos concluem que, embora a proporção do eleitorado com alguma identidade partidária esteja em torno de $50 \%$, ela é um bom preditor do voto.

Carreirão e Kinzo (2004), analisando os dados das eleições presidenciais de 1989 a 2002, concluem que a preferência partidária de um eleitor permite prever a posição no espectro ideológico do candidato em que esse eleitor irá votar, mas não permite prever a identidade desse candidato. Já a rejeição partidária teria um vínculo claro com o voto: em quase todos os casos em que um eleitor declarou rejeitar um partido ele não votava em um candidato deste partido.

Braga e Pimentel (2011) analisam os dados do ESEB de 2002, 2006 e 2010 buscando verificar o efeito da "simpatia partidária" 4 no voto. Os autores concluem que as simpatias pelo PT e pelo PSDB, os dois partidos que controlam a grande maioria dos votos nas últimas eleições presidenciais, se mostraram um dos principais componentes da explicação do voto nos seus candidatos.

Vemos assim que tanto a identificação ideológica quanto a identificação partidária ajudam a explicar a decisão do voto. Alguns dos autores examinados juntam essas duas variáveis na explicação do voto. Em outro trabalho Carreirão (2007a) examina o impacto da identificação ideológica controlando por variáveis como o sentimento partidário, a avaliação do governo, atributos dos candidatos e características do eleitor como religião, escolaridade, gênero etc. A conclusão que o autor chega é a de que a decisão do voto era determinada por fatores variados, alguns destes fatores seriam importantes para explicar o voto em um candidato mas não teriam importância para explicar o voto em outro. Nas palavras do autor:

\footnotetext{
"The variables that appeared most frequently (...) or with most considerable weight were: voters' religion, their "party sentiments", their positioning on a left-right scale, the evaluation they made of the sitting government (...) and the candidates' attributes(...)"
} (CARREIRÃO, p.90, 2007a).

\footnotetext{
${ }^{3} \mathrm{O}$ "sentimento partidário" é apreendido por meio de uma combinação de variáveis relacionadas à relação dos entrevistados com os partidos. Conforme Carreirão: "Quando um eleitor apontava um partido como aquele que representava a maneira como ele pensava, ou quando ele dizia 'gostar' de um ou mais partidos, isso foi considerado um 'sentimento positivo' em relação a este partido. Foi considerada um 'sentimento negativo' a indicação de um partido à pergunta 'em qual destes partidos o(a) sr(a). não votaria de jeito nenhum' (sendo que era lido o nome de cada um dos principais partidos e perguntado se o eleitor não votaria ou poderia votar)" (CARREIRÃO, 2007b, p.325).

${ }^{4}$ A "simpatia partidária" seria uma medida de identificação partidária mais flexível baseada na atribuição de um valor entre $0 \mathrm{e}$ 10 para o quanto o eleitor gosta de determinado partido (BRAGA e PIMENTEL, 2011, p.280).
} 
GUARNIERI, F. Comportamento eleitoral e estratégia partidária nas eleições...

Nicolau (2011) também sugere um modelo multivariado do voto, utilizando regressão logística, que integra variáveis programáticas (relacionadas à posição ideológica) e não programáticas (relacionadas à identificação partidária, avaliação de governo etc.). A conclusão do autor é que tanto características individuais (sexo, educação, idade, avaliação do governo) quanto características atribuídas pelos eleitores aos candidatos (proximidade ideológica e identidade partidária) ajudam a distinguir o apoio entre os candidatos.

Nenhum destes trabalhos leva em consideração as estratégias partidárias. Os modelos multivariados propostos até o momento nos ajudam a entender apenas parte da competição eleitoral, isto é, explicam apenas como o eleitor forma sua decisão de voto. Eles se limitam ao comportamento eleitoral. Esses modelos não nos dizem nada sobre como os partidos reagem ao modo como o eleitor vota.

A questão da estratégia dos partidos é fundamental pois, por um lado, o eleitor só pode escolher entre as alternativas que Ihe são oferecidas e, por outro, os partidos encontram limites para responder aos fatores que levam à decisão do voto. Quando os partidos optam por se coligar o número de alternativas se reduz e as escolhas possíveis estão determinadas independentes de qualquer dos fatores explicativos da decisão do voto. Mesmo sabendo como os eleitores decidem seu voto pode haver outros determinantes, como as disputas intrapartidárias, que limitam a capacidade dos partidos em responder a estes fatores.

Vemos assim que a competição política, seus resultados e suas consequências, vão bem além do comportamento eleitoral. Para entendê-la é preciso levar em conta as estratégias partidárias. Dado que o eleitor decide seu voto tomando como base a sua identificação ideológica e sua identidade partidária, entre outros fatores, como os partidos respondem a isso? Assumindo que os partidos/candidatos têm condições de mapear a distribuição das preferências dos eleitores e que conseguem identificar aqueles eleitores simpáticos à sua legenda, qual a melhor estratégia para ganhar uma eleição?

\section{Modelo Unificado do Voto}

Se todo eleitor escolhesse o candidato cujas propostas fossem as mais próximas à sua preferência e se todo eleitor tivesse preferências estruturadas, o resultado da competição eleitoral estaria determinado, pois os candidatos tenderiam a apresentar a mesma proposta em um ponto em que angariariam o apoio da maior parte do eleitorado: o ponto ideal do eleitor mediano (Downs, 1999).

Por outro lado, se todo eleitor votasse no partido com o qual teria estabelecido vínculos de ordem psicológica, no processo de socialização, o resultado eleitoral também estaria determinado de antemão: o vencedor seria aquele partido que tivesse conseguido estabelecer tais vinculações com o maior número de eleitores.

Nas eleições reais, como vimos acima, nem todo eleitor escolhe com base em suas preferências ideológicas e nem todo eleitor estabelece vínculos partidários. Além disso, embora essas duas variáveis sejam bons preditores do voto, outros fatores observáveis - como a avaliação do governo - e não observáveis - como alguns atributos dos candidatos - também têm impacto na decisão do voto. 
Todo esse conjunto de fatores pode ser reunido em um modelo de voto que nos ajude a entender as estratégias à disposição dos partidos. Adams, Merrill e Grofman (2005) propõem um modelo deste tipo o qual denominam de Modelo Unificado do Voto. Este modelo parte da seguinte função utilidade do eleitor:

$$
\mathrm{U}_{\mathrm{ik}}(\mathrm{s}, \mathrm{a})=-\mathrm{a}\left(\mathrm{x}_{\mathrm{i}}-\mathrm{S}_{\mathrm{k}}\right)^{2}+\beta \mathrm{t}_{\mathrm{ik}}+\delta \mathrm{z}_{\mathrm{i}}+\varepsilon_{\mathrm{i}}(1)
$$

Uma descrição dos componentes deste modelo nos ajudará a entendê-lo melhor. O primeiro componente $-a\left(x_{i}-s_{k}\right)_{2}$ nos diz simplesmente que um eleitor prefere propostas $s_{k}$ próximas de seu ponto ideal $x_{i}$. O formato quadrático deste componente nos indica que a preferência do eleitor decresce cada vez mais rápido conforme a proposta do candidato se afasta do seu ponto ideal.

Esse primeiro componente visto de forma isolada corresponde ao modelo espacial desenvolvido por Downs, na sua forma determinista. A decisão do voto seria tomada única e exclusivamente com base na distância entre a proposta do candidato e o ponto ideal do eleitor ${ }^{5}$.

$O$ segundo e o terceiro componente $\beta t_{i k}$ e $\delta z_{i}$ do modelo da Adams et al (2005) apreendem os fatores não programáticos. Entre eles estão fatores que variam com os candidatos, como a identificação partidária, e fatores que não variam com os candidatos, isto é, características individuais como a avaliação que o eleitor tem do governo, características demográficas e sociais.

Adams et al (2005) mostram que quando se introduz $\beta t_{i k}$ no modelo espacial de Downs é possível demonstrar que os candidatos possuem incentivos para aproximar sua proposta do ponto mediano de seus apoiadores, isto é, os candidatos não se posicionaram no ponto do eleitor mediano. Adams et al também mostram que essa proposta não vai corresponder exatamente ao ponto mediano de seu apoiador, pois é sempre possível receber algum apoio de eleitores identificados com outros partidos quando se adota uma posição mais moderada.

Também é possível que os partidos adotem posições ainda mais longe do centro quando os eleitores descontam a capacidade de um candidato em cumprir com o que está prometendo. Para conquistar o voto deste eleitor o candidato terá que propor uma política que leve em conta este desconto, portanto, uma política em um ponto mais extremo do que o ponto deste eleitor.

Por fim, temos um componente $\varepsilon_{i}$ que engloba outros fatores não observados que faz com que os eleitores decidam votar neste ou naquele candidato, como fatores conjunturais e idiossincráticos.

O eleitor escolhe a alternativa que Ihe garanta maior utilidade. A probabilidade de um eleitor votar em determinado partido é dada por:

$P_{i k}(s, a)=\frac{\exp \left\{U_{i k}(s, a)\right\}}{\sum_{k=1}^{K} \exp \left\{U_{i k}(s, a)\right\}}, \forall i, k$

Adams et al mostram que a função utilidade (1) e a probabilidade (2) podem ser utilizadas para se achar um equilíbrio de Nash no posicionamento dos partidos no contínuo esquerda-direita, isto é, um posicionamento onde nenhum dos partidos pode aumentar sua proporção de votos mudando de estratégia. Essa posição ótima é dada por:

\footnotetext{
${ }^{5} \mathrm{Na}$ sua forma probabilística -a(xi-sk)²+єi existiriam fatores não programáticos - que não são baseados na avaliação das propostas - que fariam com que os candidatos não necessariamente convergissem para o centro.
} 
GUARNIERI, F. Comportamento eleitoral e estratégia partidária nas eleições...

$$
s_{k}=\frac{\sum_{i} P_{i k}(s, a)\left(1-P_{i k}(s, a)\right) x_{i}}{\sum_{i} P_{i k}(s, a)\left(1-P_{i k}(s, a)\right)}
$$

Os autores descrevem a competição eleitoral como uma sequência de "jogadas" onde os partidos/candidatos, um por vez, posicionam sua proposta em um contínuo esquerda-direita com o objetivo de maximizar seus votos, levando em consideração a função utilidade dos eleitores, conforme o modelo descrito acima, e a posição das propostas dos outros partidos/candidatos. Essa sequência termina quando nenhum partido pode conquistar mais votos mudando a posição de suas propostas, atingindo um equilíbrio de Nash.

O algoritmo proposto por Adams et al (2005) para determinar a posição de equilíbrio dos partidos tem como base essa sequência de jogadas. Empiricamente, para se chegar à posição dos candidatos primeiro se estimam os parâmetros da função utilidade do eleitor (1) e então se utilizam estes parâmetros como input para o algoritmo calcular a posição ótima dos candidatos $\mathbf{s}_{k}$.

Uma forma de se estimar os parâmetros da função utilidade é utilizando um modelo de escolha onde a razão de chance de se escolher um candidato comparado a outro depende de características do eleitor que não variam com os candidatos (sexo, idade, escolaridade) e de características que variam com o candidato (proximidade ideológica e identidade partidária) ${ }^{6}$.

O modo como este modelo é estimado e como o algoritmo de Adams et al (2005) funciona ficará mais claro na próxima seção onde o utilizaremos para examinar as estratégias dos principais candidatos nas três últimas eleições para presidente do Brasil.

\section{Estratégias partidárias nas eleições presidenciais brasileiras de 2002 a 2010}

A eleição presidencial brasileira de 2002 tem grande importância na história recente do país, pois marca a chegada da esquerda ${ }^{7}$ ao poder com a vitória de Lula do Partido dos Trabalhadores (PT). Apesar disso existem poucas análises que procuram explicar como se deu essa vitória (NICOLAU, 2011).

Em uma destas análises Carreirão (2004) interpretou a vitória de Lula como fruto mais de um descontentamento com o governo de Fernando Henrique Cardoso que propriamente de uma guinada do eleitorado brasileiro em direção à esquerda. Lula teria conquistado os votos daqueles que rejeitavam o governo por ter conseguido neutralizar dois fatores ligados à rejeição a sua candidatura nas eleições anteriores: seu radicalismo e seu despreparo.

O PT teria vencido por que teria moderado seu discurso, sintetizado na "carta aos brasileiros", e porque teria se aliado com forças mais à direita no espectro ideológico, como o Partido Liberal (PL) de José Alencar, candidato a vice na chapa de Lula.

Singer (2010), na mesma linha, ressalta a mudança do discurso petista e defende que esse posicionamento estratégico do PT, animado por um novo espírito, o "espírito do Anhembi", em referência ao local da reunião do diretório nacional do PT que lançou a "carta aos brasileiros", teria atraído não só o voto da burguesia como também o voto do "subproletariado".

\footnotetext{
${ }^{6}$ Adams et al (2005) sugerem o uso de um modelo logit misto, isto é, um modelo logit multinomial com variáveis explicativas no nível individual e no nível das alternativas. Esses autores demonstram que o uso deste tipo de modelo não traz resultados significativamente diferentes com relação a modelos que relaxam a premissa da independência de alternativas irrelevantes.

7 Sigo aqui a classificação de Power e Zucco (2009).
} 
De fato nas eleições anteriores de 1989, 1994 e 1998 o PT havia restringido seu arco de alianças a partidos de esquerda como o PCdoB e PSB. Em 2002, como vimos, o PT teria adotado uma posição mais ao centro se aliando ao PL. O PSB parece aproveitar a abertura de espaço à esquerda e, pela primeira vez, rompe a aliança com o PT lançando Anthony Garotinho como candidato.

No campo do centro à direita o PSDB, partido da situação, reina absoluto embora sem o apoio formal do PFL, seu aliado nas eleições de 1994 e 1998. O único concorrente neste espectro ideológico seria o candidato Ciro Gomes, do PPS, antigo integrante do PSDB.

A Figura 1 mostra a distribuição dos principais candidatos a presidente em 2002 conforme a percepção dos eleitores ${ }^{8}$. Nela vemos que os eleitores percebiam as propostas de Lula mais à esquerda e as de Serra mais à direita com Garotinho e Ciro se posicionando no centro.

Figura 1

Posição dos candidatos às eleições presidenciais de 2002 na escala esquerda/direita como percebida pelos respondentes

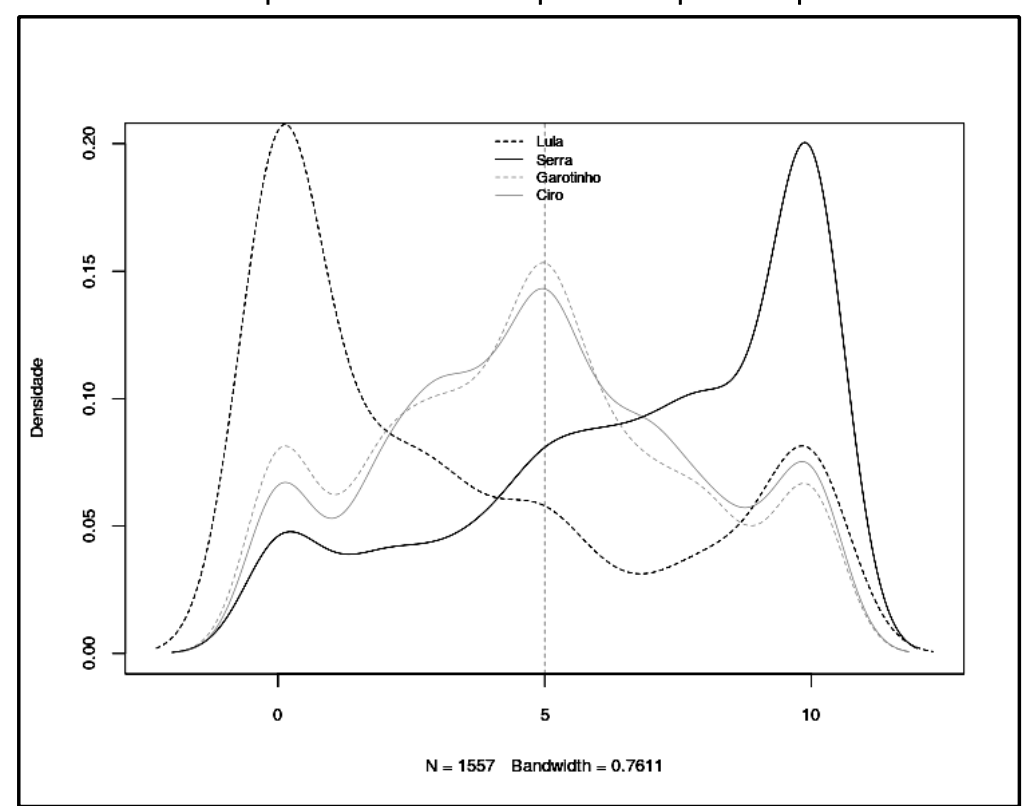

Fonte: Elaboração própria com base em dados do ESEB ( 2002).

A Figura 2 mostra a distribuição dos eleitores no espectro ideológico esquerda-direita, conforme autoposicionamento. Vemos que há certa homogeneidade entre os eleitores que se posicionam à esquerda, centro e direita com picos nos valores extremos e na mediana ${ }^{9}$.

\footnotetext{
8 Esses dados foram extraídos do ESEB 2002. Foram selecionados apenas os eleitores que votaram nos quatro principais candidatos e souberam posicioná-los no contínuo esquerda-direita, daí o $\mathrm{N}=1557$ (62\% da amostra).

9 O número de eleitores que votaram em um dos quatro principais candidatos e que souberam se posicionar no contínuo esquerda-direita foi de 1515 (60\% da amostra).
} 
Figura 2

Frequência do autoposicionamento na escala esquerda/direita dos respondentes

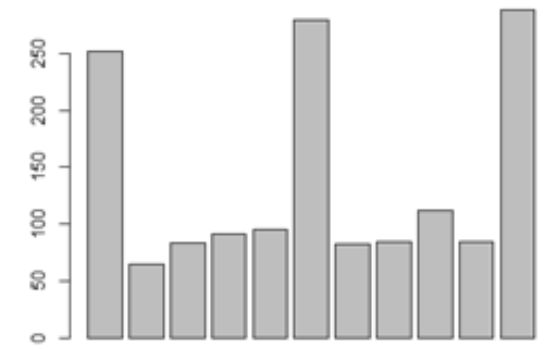

$\begin{array}{lllllllllll}0 & 1 & 2 & 3 & 4 & 5 & 6 & 7 & 8 & 9 & 10\end{array}$

Fonte: Elaboração própria com base em dados do ESEB ( 2002)

Com base nas Figuras 1 e 2 e supondo que o eleitor apenas se importa com as propostas dos candidatos, podemos ver por essa configuração que Ciro e Garotinho seriam "prensados" por Lula e Serra, conforme a teoria da entrada estratégica (PALFREY, 1984). Enquanto Lula garantiria o voto de todos os eleitores posicionados entre o ponto 0 e o ponto 4, Serra garantiria o apoio dos eleitores entre os pontos 6 e 10. Ciro e Garotinho dividiriam os votos no ponto 5 e não passariam para o segundo turno.

Mas essas figuras sozinhas não nos dizem muito sobre a motivação do eleitor. Para saber se o eleitor em 2002 levou apenas em consideração a posição dos candidatos ou se outros fatores entraram no cálculo do voto precisamos recorrer a uma análise onde todos esses fatores são examinados em conjunto.

Para isso vamos estimar os parâmetros de um modelo que prevê a razão de chance do voto em um candidato comparado com outro em função da proximidade ideológica, identidade partidária, avaliação do governo, sexo, idade e escolaridade:

$$
\begin{aligned}
\pi_{i j}= & \frac{\exp \left\{\theta_{i j}\right\}}{\sum_{k=1}^{K} \exp \left\{\theta_{i k}\right\}} \\
& \text { Onde } \\
\theta_{i j}= & \beta_{1} \text { prox }+\beta_{2} \text { partyID }+\gamma_{1} \text { gov } v_{\text {perf }}+\gamma_{2} \text { fem }+\gamma_{3} \text { age }+\gamma_{4} \text { esc }
\end{aligned}
$$

A proximidade ideológica (prox) é uma função da distância entre o autoposicionamento do eleitor e a posição percebida do candidato e varia de $\cdot 100$, mais distante, até 0 , mais próximo. A identidade partidária (party/D) é uma combinação de respostas a questões sobre se o eleitor se sentia representado por algum dos partidos dos candidatos que disputavam a eleição, se gostava de algum destes partidos ou se gostava pelo menos um pouco de algum partido. Da resposta a estas questões foram extraídos indicadores de preferência para cada um dos partidos na disputa. Sexo é uma variável dicotômica que assume o valor 1 quando se trata de uma eleitora e 0 quando de um eleitor. A idade 
(age) foi agrupada em três faixas, a primeira de 16 a 24 anos recebeu o valor de $\cdot 1$, a segunda, de 25 a 34 anos recebeu o valor 0 e a terceira, 35 anos ou mais, recebeu o valor +1 . A escolaridade (ESC) foi agrupada em 5 categorias com os seguintes valores: -2 : sem instrução, -1: até quarta série, 0 : de $5^{\mathrm{a}}$ a $8^{\mathrm{a}}$ série, +1: $2^{\circ}$ grau, +2: superior ou mais. A avaliação do governo (gov_perf) varia de -2: péssimo a 3: ótimo passando por -1: ruim, 0: regular para ruim, +1:regular para bom, +2: bom.

A Tabela 1 mostra os valores estimados dos coeficientes com os efeitos de proximidade ideológica e de identidade partidária variando com os candidatos:

Tabela 1

\begin{tabular}{|l|r|r|}
\hline \multicolumn{1}{|c|}{ Variável } & Estimate & Std. Error \\
\hline pps:(intercept) & $-0,50$ & 0,20 \\
\hline psb:(intercept) & $-0,24$ & 0,18 \\
\hline pt:(intercept) & 0,92 & 0,16 \\
\hline pps:gov_perf & $-0,32$ & 0,07 \\
\hline psb:gov_perf & $-0,31$ & 0,06 \\
\hline pt:gov_perf & $-0,42$ & 0,05 \\
\hline pps:fem & $-0,15$ & 0,22 \\
\hline psb:fem & $-0,14$ & 0,19 \\
\hline pt:fem & $-0,30$ & 0,16 \\
\hline pps:age & 0,05 & 0,14 \\
\hline psb:age & $-0,06$ & 0,12 \\
\hline pt:age & $-0,16$ & 0,10 \\
\hline pps:educ & 0,18 & 0,11 \\
\hline psb:educ & 0,09 & 0,09 \\
\hline pt:educ & $-0,09$ & 0,08 \\
\hline psdb:partylD & 0,96 & 0,27 \\
\hline pps:partylD & 2,98 & 1,17 \\
\hline psb:partylD & 3,43 & 1,12 \\
\hline pt:partylD & 2,35 & 0,18 \\
\hline psdb:prox & 0,01 & 0,00 \\
\hline pps:prox & 0,01 & 0,00 \\
\hline psb:prox & 0,00 & 0,00 \\
\hline pt:prox & 0,01 & 0,00 \\
\hline
\end{tabular}

A Tabela 1 mostra que a proximidade ideológica aumenta significativamente a chance de o eleitor votar em um dos candidatos do PT, PSDB ou PPS, não tendo impacto significativo no caso do PSB. Nos três primeiros casos um aumento de dez pontos na escala de proximidade significa um aumento de $2.5 \%$ na probabilidade do eleitor votar no candidato.

No entanto, mais forte que a proximidade na determinação do voto do eleitor é a identificação partidária. No caso de Lula, a identificação com o PT aumentava em 59\% a probabilidade de ele receber o voto do eleitor. Já no caso de Garotinho a identificação com o PSB aumentava em 85\% esta probabilidade.

A avaliação do governo tem o sinal negativo conforme esperado, isto é, quanto melhor a avaliação do governo de Fernando Henrique menor a probabilidade de se votar em outro candidato comparado com a probabilidade de se votar em Serra.

Portanto, esse modelo indica que o eleitor em 2002 orientou seu voto pela sua identidade partidária, pela avaliação do governo, por atributos dos candidatos e, em menor grau, pela proximidade 
com as propostas dos candidatos, o que corrobora os achados de Carreirão (2004) e de Holzhacker e Balbachevsky (2007).

Esses coeficientes, além de dar uma ideia da motivação do eleitor, também nos ajudam a estimar a melhor estratégia dos candidatos frente a essa motivação. Para isto utilizamos o algoritmo de Adams et al (2005) implantado no pacote NOPP (CURINI e IACUS, 2012). Os coeficientes são passados para o algoritmo que calcula a posição dos candidatos que maximiza seus votos. A Figura 3 mostra o resultado de duas estimativas destas posições.

Na Figura 3a, os candidatos podem se mover livremente na escala esquerda-direita, isto é, um candidato como Lula, do PT, pode propor políticas tanto à esquerda quanto à direita do espectro político levando em conta apenas os parâmetros estimados no modelo acima e buscando somente maximizar seus votos. Na Figura 3b, restringimos Lula à esquerda, isto é, consideramos que o PT, além de maximizar votos, também se preocupa com outros fatores como sua imagem ideológica, principalmente com a imagem que seus eleitores têm dele.

Figuras 3a e 3b

Posição otima dos candidatos nas eleições de 2002 como predita pelo algoritmo de Adam et al e implantada no pacote NOPP

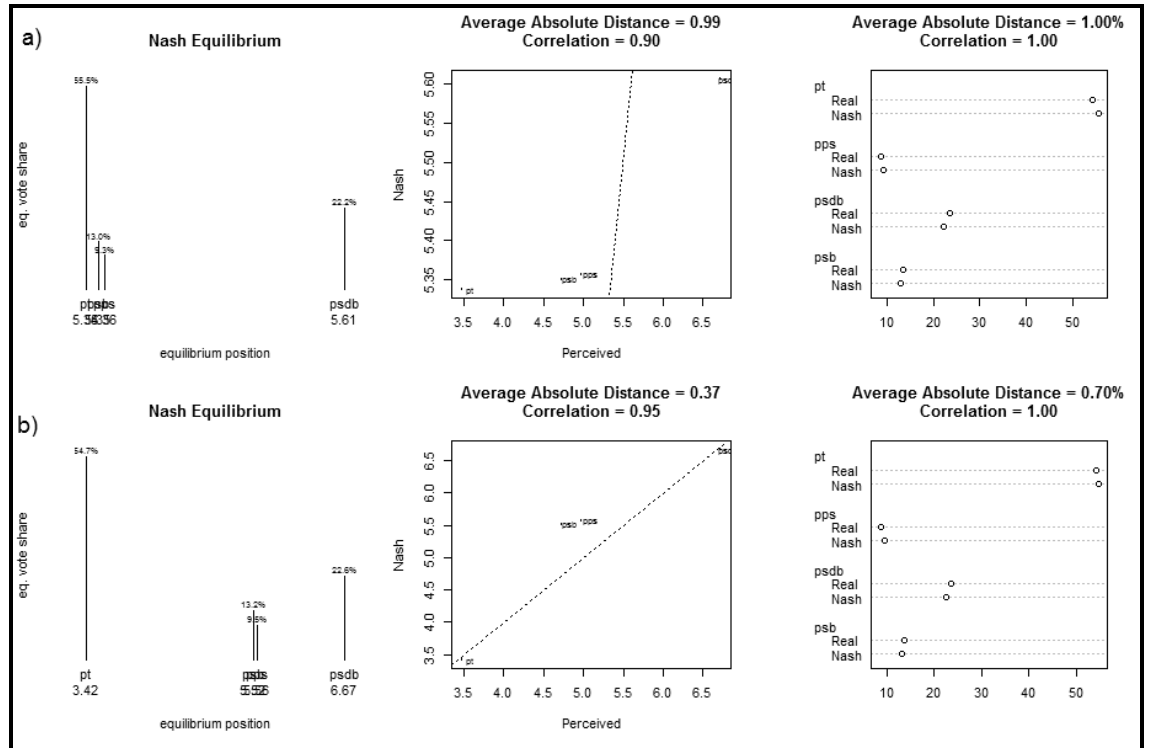

Fonte: Elaboração própria a partir de dados do ESEB (2002).

Nota: À esquerda temos a posição predita, no centro temos a relação entre aposição predita e a posição como percebida pelos respondentes do ESEB 2002 e à direita temos a relação entre a votação (\%) predita e a proporção de respondentes do ESEB 2002 que escolheu determinado candidato Na Figura 3b a posição do PT foi fixada a priori.

A Figura 3a mostra que a posição de equilíbrio no modelo em que os candidatos apenas buscam maximizar seus votos tem alta correlação (0.90) com a posição "real", isto é aquela percebida 


\section{OPINIÃO PÚBLICA, Campinas, vol. 20, no 2, agosto, 2014, p. 157-177}

pelos eleitores, e a proporção estimada de votos que os candidatos receberiam nesta posição também tem alta correlação (1.00) com a proporção de votos na amostra ${ }^{10}$.

Apesar da alta correlação Lula está na posição 5.34 em uma escala que vai de 0 a 10, onde 0 é a posição mais à esquerda, bem mais ao centro do que a posição deste candidato como percebida pelos eleitores que é de 3.48. 0 gráfico mais à esquerda da Figura 3a mostra a distribuição das posições sem restrição. Isto pode estar ocorrendo por pelo menos dois motivos: ou o partido está ideologicamente "preso" a uma posição mais extrema, ou o eleitor está descontando a capacidade do partido em realizar a política prometida. Quando há esse tipo de desconto o partido deve propor políticas mais extremas do que a posição ótima do ponto de vista da maximização de votos para garantir a mesma fatia de votos.

A Figura 3b leva em conta estes dois fatores. Ela mostra a posição estimada $\cdot 3.42$ - quando restringimos a posição do PT à esquerda e atribuímos um desconto de $50 \%$ na capacidade do partido em realizar a proposta prometida. Vemos que não só as correlações aumentam, como também as distâncias entre as posições estimada e real diminuem, assim como diminui a diferença entre a proporção de votos estimada e a proporção de votos da amostra, o que indica melhoria no modelo. 0 gráfico com a posição dos partidos na Figura 3b mostra o PT mais à esquerda dessa vez, mais conforme com a percepção do eleitor.

Assim vemos que, se, em 2002, o PT moderou o discurso, isso não se refletiu na posição percebida pelos eleitores. Se o partido tivesse adotado uma atitude unicamente pragmática, buscando apenas maximizar sua proporção de votos, teria se posicionado mais ao centro do contínuo esquerda direita. $O$ fato de não tê-lo feito demonstra que o partido ainda se importa com sua reputação entre os eleitores ou responde às pressões internas de militantes mais ideológicos.

A posição dos outros partidos no modelo onde o que importa é maximizar os votos é muito próxima à percebida pelos eleitores. Isto indica que esta é a maior motivação estratégica destes partidos. O PSDB controla toda a centro-direita, assim como o PT controla a centro-esquerda. Isto ajuda a explicar porque estes dois partidos foram os que passaram para o segundo turno das eleições e mostra a importância da coordenação pré-eleitoral que impede a entrada de partidos mais à esquerda do PT ou mais à direita do PSDB. O que restou ao PPS e PSB foi dividir uma parte da região central do contínuo ideológico.

Para verificar até que ponto o PT está preso à esquerda, bem como o efeito de um concorrente à sua esquerda vamos examinar seu posicionamento em 2006. A Figura 4 mostra a posição dos partidos conforme percebida pelos eleitores. Notamos duas diferenças em relação a 2002. Em primeiro lugar os eleitores variam muito na classificação de Lula no contínuo esquerda-direita em 2006. A maioria ainda classifica Lula à esquerda. Mas não são poucos os que o posicionam no centro e à direita. De fato, enquanto em 2002 os eleitores percebiam Lula no ponto médio 3,47, em 2006 ele passou a ocupar o ponto 4,36 , mais ao centro.

A segunda diferença é a candidatura de Heloísa Helena, ex-integrante do PT que, ao romper com este partido, funda o PSOL e se lança candidata disputando o mesmo nicho do PT. Sua posição percebida pelos eleitores estava no ponto médio 3,24.

\footnotetext{
${ }^{10} \mathrm{Na}$ amostra utilizada as proporções de votos eram as seguintes (valores arredondados): Lula $=54 \%$, Serra $=24 \%$, Garotinho $=$ $14 \%$ e Ciro $=9 \%$
} 
Figura 4

Posição dos candidatos às eleições presidenciais de 2006 na escala esquerda/direita como percebida pelos respondentes

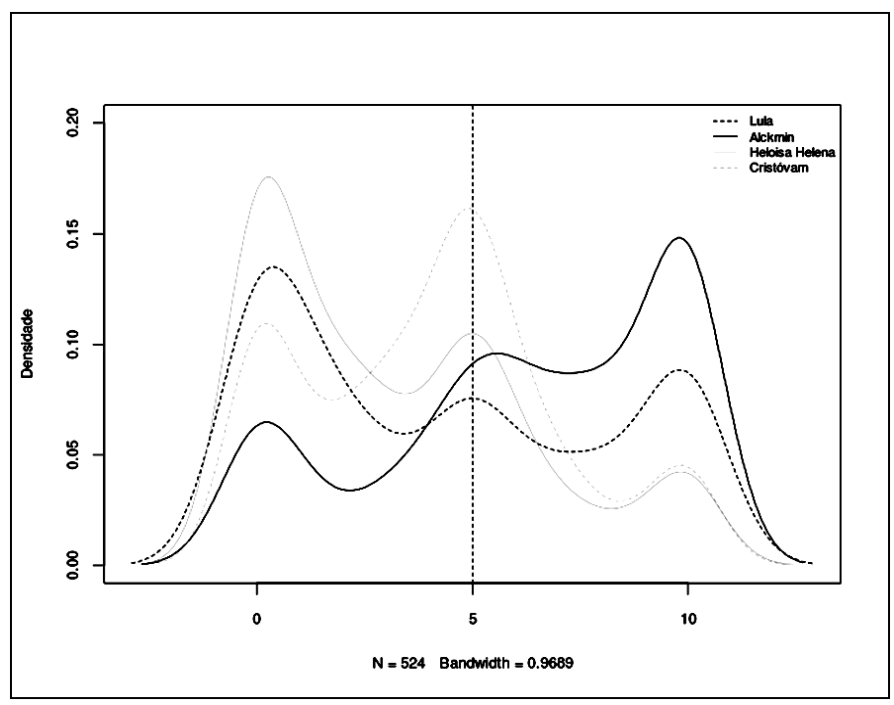

Fonte: Elaboração própria a partir de dados do ESEB (2006).

A Figura 5 mostra o autoposicionamento dos eleitores em 2006. Vemos que a maior parte se posicionou no centro e na direita do contínuo ideológico. 0 que indica que a melhor estratégia para um candidato que se importa exclusivamente em maximizar seus votos seria se posicionar próximo ao eleitor mediano (posição 5).

Figura 5

Frequência do autoposicionamento na escala esquerda/direita dos respondentes

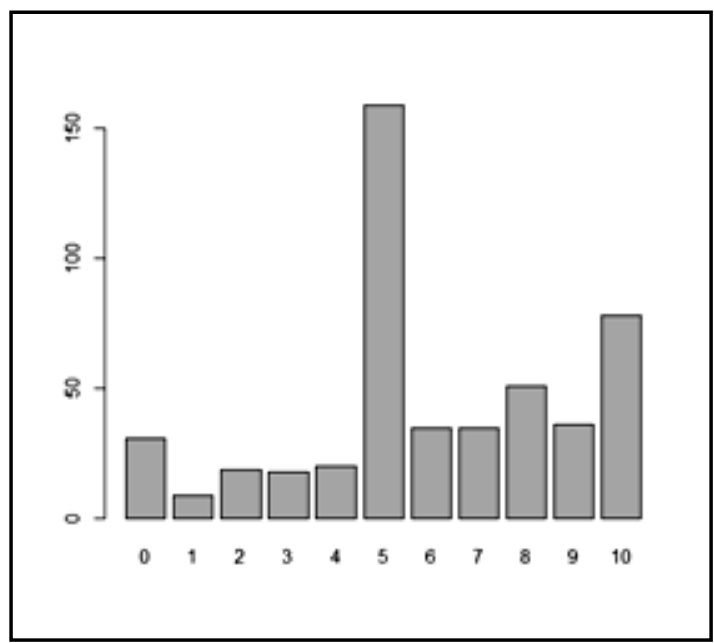

Fonte: Elaboração própria a partir de dados do ESEB (2006).

A Figura 6a mostra o posicionamento dos partidos obtido utilizando o NOPP. Vemos que o modelo que não restringe as posições dos partidos mais uma vez traz Lula mais à direita do que sua 
posição percebida (6,06 contra 4,36). A distância entre posição prevista e percebida é ainda maior no caso de Heloísa Helena, 6,05 contra 3,24. Isso ocorre porque, como notamos anteriormente, a proporção de votos conquistada por estes candidatos só seria compatível com um posicionamento mais ao centro, se os partido se importassem apenas com os votos. Mais uma vez parece não ser isso o que ocorre.

Figuras $6 a$ e $6 b$

Posição ótima dos candidatos nas eleições de 2006 como predita pelo algoritmo de Adams et al e implantada no pacote NOPP

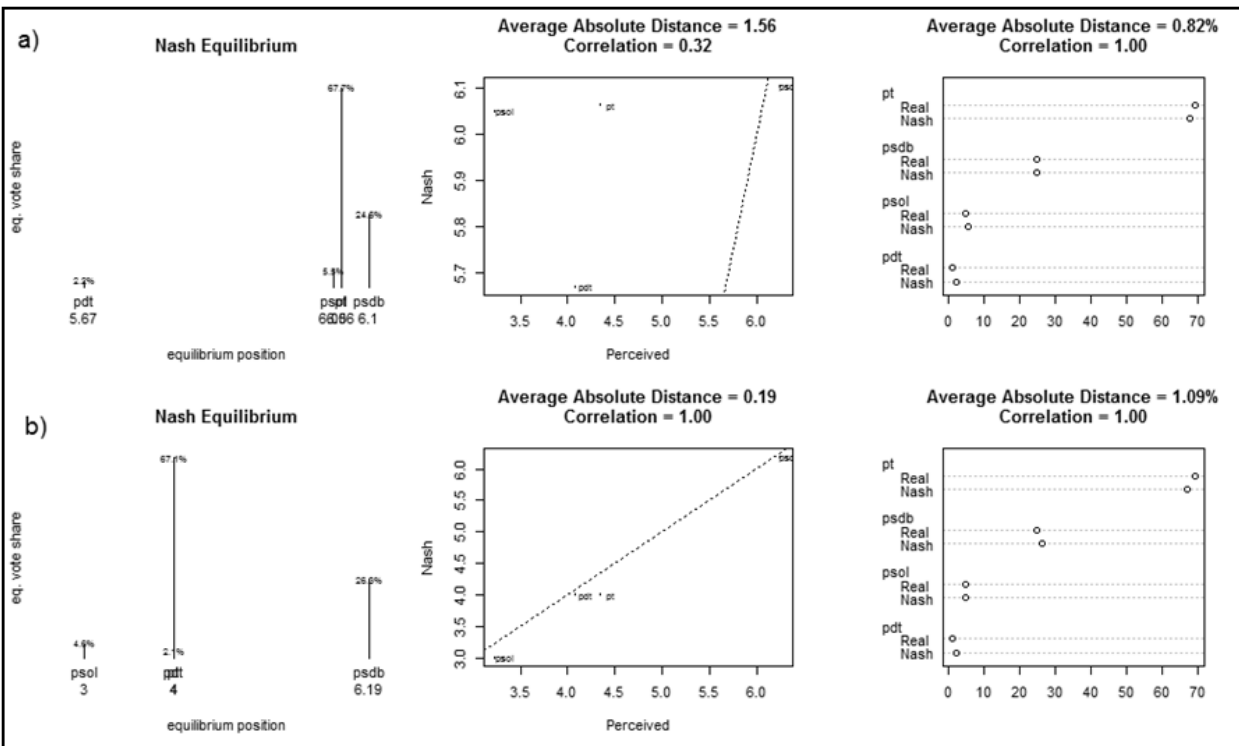

Fonte: Elaboração própria a partir de dados do ESEB (2006).

Nota: À esquerda temos a posição predita, no centro temos a relação entre aposição predita e a posição como percebida pelos respondentes do ESEB 2006 e à direita temos a relação entre a votação (\%) predita e a proporção de respondentes que escolheu determinado candidato Na Figura $6 \mathrm{~b}$ a posição do PT, PDT e PSOL foram fixadas a priori.

A Figura 6b traz um modelo onde restringimos a posição de Lula, Heloísa Helena e Cristóvam Buarque à esquerda. Vemos que neste modelo as posições estimada e percebida são praticamente as mesmas. Desta vez não parece ser plausível que esta posição mais extrema com relação à posição de uma estratégia que visa maximizar os votos se deva ao desconto da capacidade em implantar as políticas prometidas. Trata-se da reeleição de Lula que contava com alta aprovação. Também não parece que Lula se colocava mais à esquerda para agradar seus simpatizantes, pois se, em 2002, a posição média dos eleitores que se identificavam com o PT era 4,6, em 2006, ela passara para 6,9. Uma hipótese é a de que o posicionamento percebido de Lula se deve mais à necessidade de responder à necessidade de garantir o apoio de seu partido ${ }^{11}$.

As posições estimadas na Figura 6b mostram que Lula teria mantido seu domínio sobre a centro-esquerda. Alckmin, candidato do PSDB, ocupou numa posição mais à direita do que Serra em

\footnotetext{
11 Roemer (2006) propõe um modelo de competição política onde os partidos se dividem entre lideranças pragmáticas e militantes ideológicos. A posição dos partidos dependeria da barganha entre estes dois grupos.
} 
2002 o que deve ter causado a perda de algum voto para o PT, já que não haviam outros partidos no centro como em 2002.

A questão que fica é por que Cristovam Buarque não conseguiu mais votos já que adotou uma posição percebida muito próxima ao PT. Os coeficientes do modelo de explicação do voto para 2006 nos permitem responder a esta questão e são apresentados na Tabela 2:

Tabela 2

\begin{tabular}{|c|c|c|}
\hline Variável & Estimate & Std. Error \\
\hline pdt:(intercept) & $.3,79$ & 0,70 \\
\hline psdb:(intercept) & $-1,58$ & 0,27 \\
\hline psol:(intercept) & $-3,26$ & 0,56 \\
\hline pdt:gov_perf & 1,52 & 0,55 \\
\hline psdb:gov_perf & 2,20 & 0,30 \\
\hline psol:gov_perf & 1,69 & 0,42 \\
\hline pdt:fem & 0,64 & 0,70 \\
\hline psdb:fem & 0,86 & 0,31 \\
\hline psol:fem & 1,66 & 0,57 \\
\hline pdt:age & 0,41 & 0,29 \\
\hline psdb:age & 0,19 & 0,13 \\
\hline psol:age & 0,40 & 0,22 \\
\hline pdt:educ & 0,50 & 0,17 \\
\hline psdb:educ & 0,15 & 0,08 \\
\hline psol:educ & 0,28 & 0,12 \\
\hline pt:partyID & 2,83 & 0,48 \\
\hline pdt:partyID & 2,34 & 0,96 \\
\hline psdb:partylD & 2,30 & 0,49 \\
\hline psol:partyID & 5,57 & 1,44 \\
\hline pt:prox & 0,02 & 0,02 \\
\hline pdt:prox & 0,04 & 0,04 \\
\hline psdb:prox & 0,04 & 0,02 \\
\hline psol:prox & 0,04 & 0,02 \\
\hline
\end{tabular}

As variáveis explicativas são as mesmas do modelo para 2002, com a exceção da preferência partidária que agora está invertida e vai de ótimo para péssimo. Vemos pelos coeficientes que mais do que a proximidade com relação às propostas dos candidatos o eleitor valoriza a identificação partidária, 
a avaliação do governo e, ainda mais forte que estas, certos atributos dos candidatos não incluídos no modelo e apreendidos pelos interceptos.

Cristovam Buarque teve menos votos que os demais porque, ao apresentar políticas no mesmo ponto que Lula, foi atropelado pela aprovação do governo e pela sua grande popularidade. Heloísa Helena conquistou um pouco mais de votos do que Cristovam porque se posicionou mais à esquerda que Lula roubando um pouco dos votos deste.

A Figura 7 mostra que em 2010 o eleitor mediano se tornou mais conservador se posicionando no ponto 7. Também a candidata do PT Dilma Rousseff vai adotar uma posição um pouco mais conservadora no ponto 4.95, mas ainda à esquerda do eleitor mediano. Serra nesta eleição adota a mesma posição de Alckmin em 2006 (6,2). A novidade é Marina Silva que adota uma posição central $(4,82)$ embora um pouco mais à esquerda do que a do PT.

Figura 7

Posição dos candidatos às eleições presidenciais de 2010 na escala esquerda/direita como percebida pelos respondentes

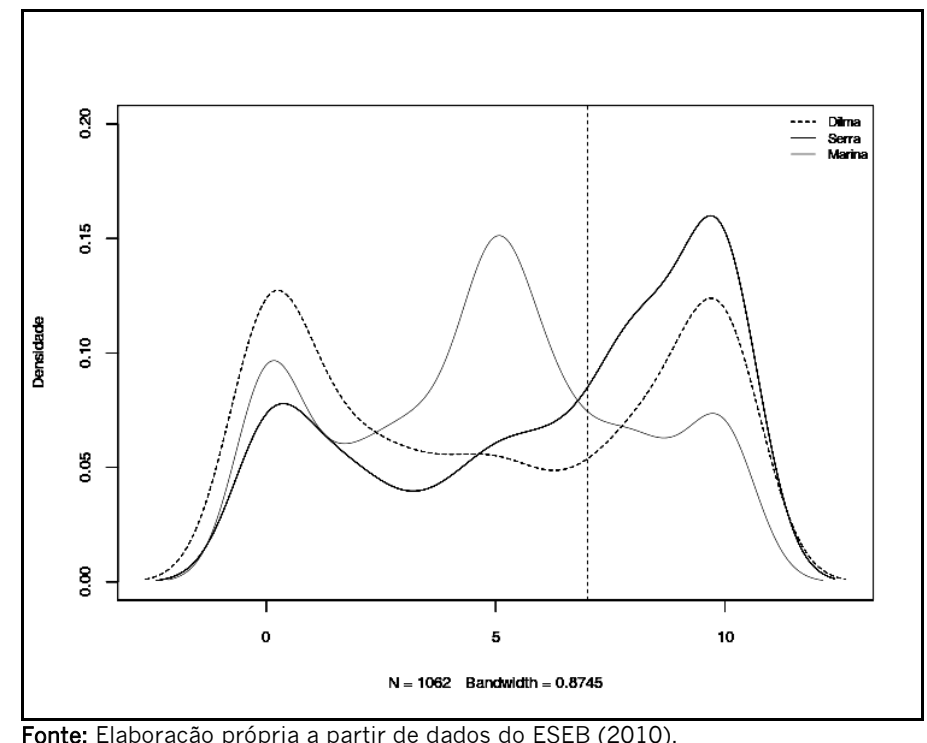

A posição dos partidos estimada pelo NOPP nos mostra mais uma vez que o eleitor percebe a candidata do PT mais à esquerda do que o modelo maximizador de votos previa, conforme a Figura 8 a. Quando fixamos a posição do PT à esquerda o modelo melhora consideravelmente, conforme a Figura 8b. Portanto, o PT continua preso à esquerda por mais que tenha caminhado em direção ao centro nas últimas eleições. 
Figuras $8 \mathrm{a}$ e $8 \mathrm{~b}$

Posição 6tima dos candidatos nas eleições de 2010 como predita pelo algoritmo de Adams et al e implantada no pacote NOPP

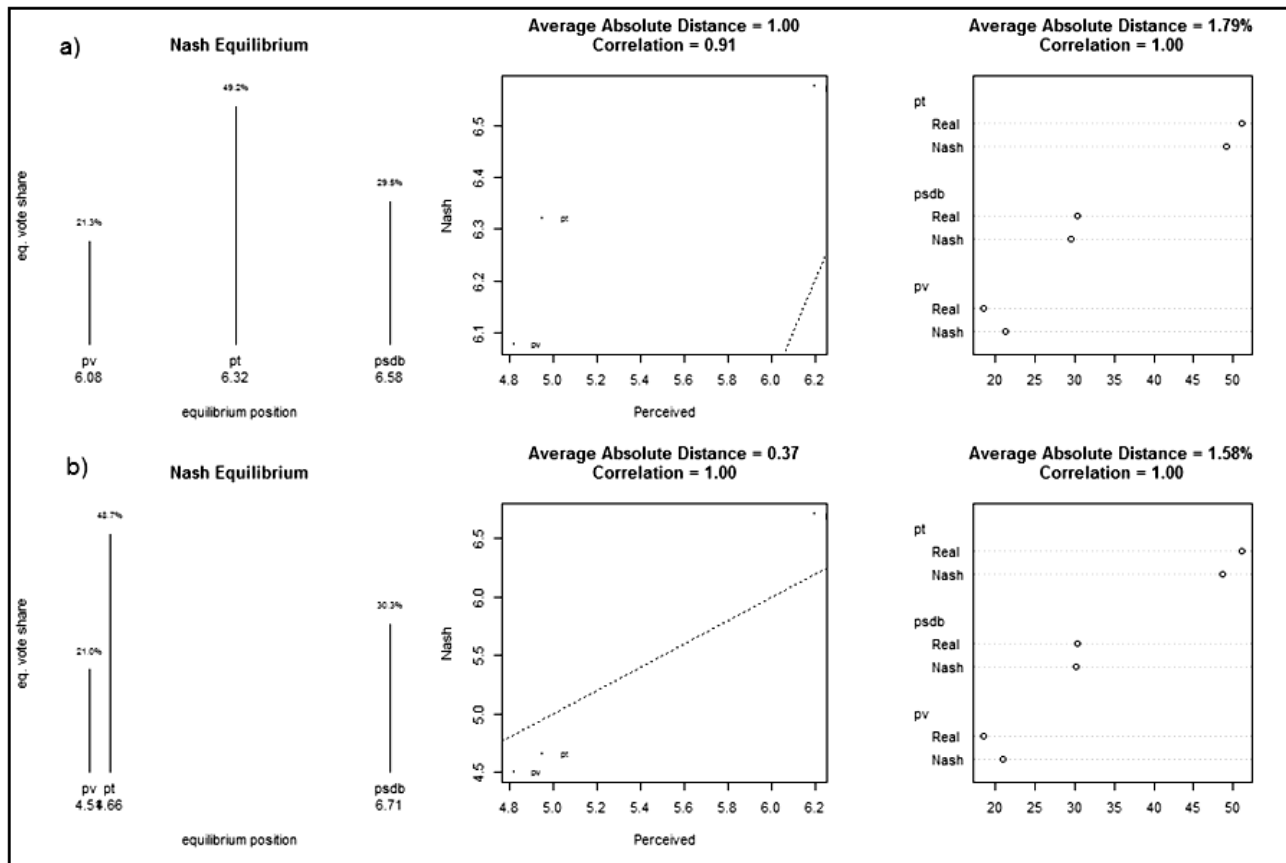

Fonte: Elaboração própria a partir de dados do ESEB (2010).

Nota: À esquerda temos a posição predita, no centro temos a relação entre aposição predita e a posição como percebida pelos respondentes do ESEB 2010 e à direita temos a relação entre a votação (\%) predita e a proporção de respondentes que escolheu determinado candidato. Na Figura 6b a posição do PT e PV foram fixadas a priori.

O fato de Dilma ter vencido a eleição mesmo sem se posicionar próxima à região onde se posicionam a maior parte dos eleitores e o fato de Serra ter sido derrotado mesmo se posicionando mais próximo ao eleitor mediano indica, mais uma vez, que a proximidade ideológica não é o fator mais importante na decisão do voto.

No entanto, os coeficientes do modelo de explicação do voto em 2010, apresentados na Tabela 3, são bem diferentes dos coeficientes dos modelos para 2006 e 2002. Enquanto naqueles anos Lula possuía uma vantagem, devido a características não observadas, com relação a outros candidatos, em 2010 essa vantagem é de Serra em relação à Dilma, o que pode ser visto analisando os interceptos. O efeito da identificação partidária é menor do que o encontrado nos outros anos e muito similar entre os partidos. 
Tabela 3

\begin{tabular}{|l|r|r|}
\hline \multicolumn{1}{|c|}{ Variável } & Estimate & Std. Error \\
\hline psdb:(intercept) & 1,06 & 0,20 \\
\hline pv:(intercept) & 0,28 & 0,22 \\
\hline psdb:gov_perf & 1,52 & 0,18 \\
\hline pv:gov_perf & 1,02 & 0,18 \\
\hline psdb:fem & 0,13 & 0,18 \\
\hline pv:fem & 0,25 & 0,19 \\
\hline psdb:age & $-0,03$ & 0,07 \\
\hline pv:age & $-0,07$ & 0,07 \\
\hline psdb:educ & 0,05 & 0,04 \\
\hline pv:educ & 0,31 & 0,05 \\
\hline pt:partylD & 1,84 & 0,18 \\
\hline psdb:partylD & 1,81 & 0,27 \\
\hline pv:partylD & 1,67 & 0,37 \\
\hline pt:prox & 0,01 & 0,01 \\
\hline psdb:prox & 0,03 & 0,01 \\
\hline pv:prox & 0,01 & 0,01 \\
\hline
\end{tabular}

Uma variável no modelo que ajuda a entender a vitória de Dilma é a avaliação do governo Lula. Se todos os eleitores avaliassem o governo Lula apenas como "bom" a proporção de votos de Dilma cairia dos previstos $49 \%$ para $29,8 \%$ e a diferença iria para Serra. Já se todos avaliassem o governo como ótimo a proporção de votos da candidata do PT subiria para 55,6\% e ela ganharia no primeiro turno.

Outra variável é a identificação partidária que, apesar de ter um efeito menor do que o encontrado em outros anos e deste efeito ser muito similar nos três partidos, é muito mais presente com relação ao PT. A proporção da amostra que diz se identificar com o PT em 2010 é de 25\% e entre aqueles que souberam identificar os candidatos no contínuo esquerda-direita chegou a $71 \%$. Se todos os eleitores se identificassem com o PT, isto é, se houvesse um aumento de $40 \%$ no número de eleitores que se identificam com o PT, a proporção prevista de votos subiria $29 \%$ indo para $77 \%$.

Assim como Nicolau(2011) vemos que podemos melhorar nosso modelo incorporando variáveis que ajudem a explicar melhor o comportamento centrífugo dos candidatos do PT e a decisão do voto ${ }^{12}$. Essas variáveis devem provir de estudos sobre competição política que privilegiem as estratégias partidárias como os de Limongi e Cortez (2010) e Guarnieri (2011).

\section{Considerações Finais}

Nas análises que se debruçaram sobre as eleições presidenciais muita ênfase foi dada ao comportamento do eleitor e pouco se tem tratado das estratégias partidárias. Apesar de trabalhos mais recentes terem procurado investigar conjuntamente as motivações programáticas e as motivações de

\footnotetext{
12 Embora as medidas de ajuste sejam de difícil interpretação em modelos categóricos nossos R2 de McFadden (um pseudo R2) foram 0.18 para 2002, 0.40 em 2006, e 0.24 em 2010.
} 
GUARNIERI, F. Comportamento eleitoral e estratégia partidária nas eleições...

ordem mais psicológica do eleitor, os partidos têm sido tratados de forma sempre marginal nestas análises.

Neste artigo, pretendi dar um primeiro passo na incorporação das estratégias partidárias entre os determinantes da competição política. Recentes avanços teóricos e metodológicos, assim como a disponibilização do Estudo Eleitoral Brasileiro - ESEB, facilitaram esta tarefa.

Utilizando o quadro teórico proposto por Adams et al (2005) verifiquei a posição que os partidos assumiram no contínuo esquerda-direita tendo em vista os parâmetros de um modelo de decisão de voto que leva em conta não só fatores programáticos como também fatores não programáticos.

Enquanto este modelo proporcionou uma boa aproximação da posição dos candidatos do PSDB e de outros partidos que se posicionaram mais ao centro e à direita, ele não foi muito preciso no posicionamento dos candidatos do PT e de outros partidos que se posicionavam mais à esquerda.

Isto indica que estes partidos se movem menos pela maximização de votos do que por outros fatores. A questão é: quais fatores estariam "prendendo" estes partidos na esquerda? Uma resposta possível poderia ser a pressão exercida pela militância partidária nos candidatos de partidos de esquerda. A posição final destes partidos seria o resultado do acordo entre lideranças pragmáticas e militantes ideológicos, como sugerido por Roemer (2006). Infelizmente, não foi possível testar esta hipótese no presente artigo.

Outro ponto que ganha realce com a análise das estratégias partidárias nas eleições presidenciais é a questão da coordenação pré-eleitoral. Se o PT é forçado a permanecer à esquerda e o PSDB ocupa uma posição mais central e se, como indicam os dados, o eleitor mediano vem ocupando posições cada vez mais à direita, o que impediria a entrada de candidatos à direita do PSDB? Uma resposta a isso seria justamente a coordenação pré-eleitoral. Uma segunda resposta seria que, como o eleitor não dá tanto peso a fatores programáticos, haveria fatores não programáticos e não identificados no modelo que fazem com que o PSDB domine este espectro ideológico. Mais uma vez, a determinação destes fatores é uma agenda em aberto para futuras pesquisas.

\section{Referências Bibliográficas}

Adams, J. F.; MerrilL, III, S.; Grofman, B. A unified theory of party competition: A cross-national analysis integrating spatial and behavioral factors. Cambridge University Press, 2005.

AdAMS, J. F.; CLARK, M.; EZROW, L.; GLASGOW, G. "Are niche parties fundamentally different from mainstream parties? The causes and the electoral consequences of Western European parties' policy shifts, 1976-1998." American Journal of Political Science, vol. 50, n³, p.513-529, 2006.

Braga, M. S. S.; PImentel, JR., J. "Os partidos políticos brasileiros realmente não importam?" Opinião Pública, vol.17, n², p.271-303, 2011.

Calvo, E.; HellwiG,T. "Centripetal and centrifugal incentives under different electoral systems." American Journal of Political Science, vol.55, n¹, p.27.41, 2011.

CARREIRÃo, Y. S. "Identificação ideológica e voto para presidente." Opinião Pública, vol. VIII, nº 1, 2002. 


\section{OPINIÃO PÚBLICA, Campinas, vol. 20, nº 2, agosto, 2014, p. 157-177}

"Relevant factors for the voting decision in the 2002 presidential election: an analysis of the ESEB (Brazilian Electoral Study) Data."Brazilian Political Science Review (Online), 1.SE: 0.0, 2007a.

"Identificação ideológica, partidos e voto na eleição presidencial de 2006." Opinião Pública, vol. 13, n², p.307.339, 2007b.

; Kınzo, M. D. G. "Partidos políticos, preferência partidária e decisão eleitoral no Brasil (1989/2002)." Dados, vol.47, $\mathrm{n}^{\circ} 1, \mathrm{p} .131 \cdot 167,2004$.

CASTRO, M. M. M. "Determinantes do comportamento eleitoral: a centralidade da sofisticação política". Tese de Doutorado em Ciência Política, IUPERJ, Rio de Janeiro, 1994.

CURINI, L.; IACUS, S. M. NOPP: Nash Optimal Party Positions. R package version 1.0.3. (2012). Disponível em: <http://cran.r.project.org/web/packages/nopp/index.html>. Último acesso em: 9 abr. 2013.

Downs, A. Uma teoria econômica da democracia. São Paulo: Edusp, 1999.

FIGUEIREDO, M. F. A decisão do voto: democracia e racionalidade. Belo Horizonte: Editora UFMG, 1991

GuarnierI, F. "A Força dos Partidos 'Fracos'”. Dados, vol.54, nº1, p.235-258, 2011

HELLWIG, T. "Explaining the salience of left-right ideology in postindustrial democracies: The role of structural economic change." European Journal of Political Research, vol.47, n6, p.687.709, 2008.

Henningsen, A.; Toome, O. "MaxLik: A package for maximum likelihood estimation". In: Computational Statistics, 26(3), p. 443-458, 2011.

HolzhaCKER, D. O.; BALBACHEVSky, E. "Classe ideologia e política: uma interpretação dos resultados das eleições de 2002 e 2006." Opinião Pública, vol. 13, n², p.283·306, 2007.

JeSSEE, S. A. "Spatial voting in the 2004 presidential election." American Political Science Review, 103, 1, p.59-81, 2009.

LIMA, JR.; O.B. Partidos, eleições e poder legislativo. In: MICELI, S. (org.). O que ler na Ciência Política brasileira (1970 1995). São Paulo: Editora Sumaré/Anpocs, 1999.

LIMONGI, F.; CoRTEZ , R. "As eleições de 2010 e o quadro partidário." Novos Estudos.CEBRAP, 88, p.21.37, 2010.

Nicolau, J. "An analysis of the 2002 presidential elections using logistic regression." Brazilian Political Science Review, 1.1, p.125.135, 2011.

Palfrey, T. R. "Spatial equilibrium with entry." The Review of Economic Studies, 51.1, p.139-156, 1984.

POWER, T.; ZUCCO JR, C. "Estimating ideology of Brazilian legislative parties, 1990-2005: a research communication." Latin American Research Review, 44, 1, p.218-246, 2009.

Roemer, J. E. Political competition: Theory and applications. Harvard University Press, 2006.

Singer, A. "A segunda alma do Partido dos Trabalhadores." Novos Estudos.CEBRAP, 88, p. 89-111, 2010.

SINGER, A. Esquerda e direita no eleitorado brasileiro: a identificação ideológica nas disputas presidenciais de 1989 e 1994. São Paulo: Edusp, 1999.

\section{Anexo}

ESEB - Estudo Eleitoral Brasileiro, 2002

Sumário:

O ESEB 2002 é um survey pós-eleitoral, organizado por Alberto Almeida e Zairo Cheibub (FGV/Opinião), Rachel Meneguello e Fernando A. Lourenço (CESOP e IFCH/UNICAMP), que realizou 2.513 entrevistas domiciliares com eleitores em todo o Brasil. O objetivo da pesquisa foi investigar as seguintes temáticas: avaliação das instituições, informação política, exposição à mídia, participação política não-eleitoral, associativismo, interesse por política, clientelismo, personalismo, autoritarismo, 
GUARNIERI, F. Comportamento eleitoral e estratégia partidária nas eleições...

corrupção, conservadorismo, liberalismo e relação entre espaço público e privado. O survey contou com suporte Institucional da UFF . Universidade Federal Fluminense.

Universo: Eleitores de todas as regiões do Brasil

Amostragem: A amostra nacional de 2.513 entrevistas domiciliares é probabilística e representativa da população brasileira adulta (a partir de 16 anos). O desenho amostral seguiu três estágios de seleção: município (sorteados segundo a divisão político-administrativa das regiões do Brasil), setor censitário e domicílio. Os dados permitem desagregação até o nível regional em 4 estratos: 1) Norte e Centro-Oeste (agregados para garantir precisão nas inferências devido ao baixo número de entrevistas); 2) Sul; 3) Sudeste; 4) e Nordeste; O plano amostral também possibilita dividir as observações em Capital e não Capital.

Fonte de Coleta: Entrevistas domiciliares

Instituição Patrocinadora: CAPES e FAPESP

Período de Referência: 10/2002 a 12/2002

Período de Coleta: 31/10/2002 a 28/12/2002

Data de Conclusão: 28/12/2002

Sumário:

ESEB - Estudo Eleitoral Brasileiro, 2006

O ESEB 2006 é uma pesquisa pós-eleitoral de natureza acadêmica associada ao Projeto Comparative Study of Electoral Systems, da University of Michigan conduzido pelo Centro de Estudos de Opinião Pública (CESOP.UNICAMP) e Ipsos Opinion. Dividido em três partes, trata dos temas Democracia, Eleições Presidenciais e Percepção dos Eleitores sobre a Localização Ideológica de Líderes Políticos.

Universo: Eleitores brasileiros em 70 municípios.

Amostragem: 1000 entrevistas

Período de Coleta: 17 a 27/12/2006

Data de Conclusão: Dezembro de 2006

Sumário:

ESEB - Estudo Eleitoral Brasileiro, 2010

O ESEB 2010 é um estudo vinculado ao projeto internacional Comparative Study of Electoral Systems (CSES), coordenado pela Universidade de Michigan (www.cses.org) e com a participação de dezenas de instituições de vários países. Contém mais de 200 variáveis, cobrindo as eleições de 2010, percepções dos eleitores sobre democracia, partidos políticos, situação econômica e social do Brasil etc. O estudo no Brasil foi conduzido pelo Centro de Estudos de Opinião Pública (CESOP.UNICAMP)/Vox Populi com suporte do CNPq.

Universo: Eleitores brasileiros

Amostragem: 2000 entrevistas

Período de Coleta: Novembro de 2010

Fernando Guarnieri · fhguarnieri@gmail.com

Submetido à publicação em abril de 2013.

Aprovado para publicação em julho de 2013. 